\title{
Frequency response function measurement of a rotor system utilizing electromagnetic excitation by a built-in motor
}

\author{
Ren YANG*, Wataru TSUNODA*, Dong HAN**, Jianpeng ZHONG** and Tadahiko SHINSHI** \\ *Department of Mechanical Engineering, Tokyo Institute of Technology \\ 4259 Nagatsuta-cho, Midori-ku, Yokohama, 226-8503, Japan \\ **Institute of Innovative Research, Tokyo Institute of Technology \\ 4259 Nagatsuta-cho, Midori-ku, Yokohama, 226-8503, Japan \\ E-mail: shinshi.t.ab@m.titech.ac.jp
}

Received: 7 July 2019; Revised: 24 January 2020; Accepted: 9 March 2020

\begin{abstract}
In this paper, we propose a practical method for evaluating the robustness and stability of rotating machines. This entails using electromagnetic excitation and measuring the frequency response functions (FRFs) of the rotor system during rotation. The difficulty of applying excitation can be solved by utilizing a built-in motor with static eccentricity and adding a sinusoidal sweep d-axis current to the motor. A test rig with a bearingless motor (BELM) was used to verify the validity of the proposed method. A consequent-pole-type BELM is a combination of a consequent-pole-type motor and a radial magnetic bearing, in which both the motor and the suspension windings are arranged in one stator core of the BELM. The center of the motor is defined by the zero-power controller and the static eccentricity is determined by the suspension control system. The FRFs measured utilizing the electromagnetic excitation generated by the motor windings was compared with reference FRFs measured utilizing the suspension windings. The natural frequencies and damping ratios were determined from the two different FRFs. The difference between the identified natural frequencies and the difference between the damping ratios for the two different FRFs were calculated. The effectiveness of measuring the dynamic characteristics of the rotor system under various rotational conditions, such as the rotational speed and eccentricity, was clarified and the differences between the measurements obtained from the two different FRFs were generally less than $7.7 \%$.
\end{abstract}

Keywords : Rotor dynamic characteristics, Frequency response functions (FRFs), Motor windings, Suspension windings, Static eccentricity, Electromagnetic excitation, Bearingless motor (BELM)

\section{Introduction}

Turbomachines driven by built-in motor, such as canned motor pumps (TEIKOKU Electric Mfg Co Ltd, 2015), compressors, and centrifugal blood pumps (Ranjit, 2008), are extremely important systems worldwide. However, the rotor dynamics of turbomachines change throughout their service life and also change with respect to internal and external conditions. Therefore, industry is investing heavily into realizing real-time health monitoring during rotation, with the aim of extending performance and maintaining the machines so that they can be operated with high stability, reliability, and durability for long periods.

With traditional inspection methods, the displacement, velocity, and acceleration of turbomachines are measured. However, the information may be insufficient for diagnosis and prognosis. Alternatively, using an excitation force to vibrate the rotor and measure the frequency response function (FRF) is a common method to monitor the dynamic characteristics, such as the natural frequency and damping ratio, of the rotor system, which can then be used to estimate the margin of stability and determine the origin of vibrations.

In FRF measurements, a few types of exciters are used. Conventionally, impact hammering and electromagnetic actuators (Aenis et al., 2002; Takahashi et al., 2012; Tsunoda et al., 2016, 2017a) are generally used, but are undesirable. Hammering a rotating body is not simple and is unrealistic because of safety. Electromagnetic exciters are able to generate the required sweep excitation force to measure the FRF from the displacement of the rotor, enabling faults to be detected 
(Aenis et al., 2002), estimates of the stability margin to be made (Tsunoda et al., 2016, 2017a), and eigenvalues to be measured (Takahashi et al., 2012). However, installation of electromagnetic actuators is inconvenient and expensive, increasing the production costs. Moreover, the motor needs a larger footprint and longer rotor-shaft. Therefore, a lowcost, space-saving, safe and real-time monitoring system for turbomachines is required.

Here, the built-in motor that supplies the torque for the turbomachine is considered as an excitation source. An extra radial force, called the unbalanced magnetic force (UMF), developed as a result of the eccentricity of the built-in motor, can be utilized. In a previous study, C. I. Lee showed the characteristics of the UMF of a brushless DC motor (Lee and Jang, 2008). Factors, such as the non-uniform magnetization of a permanent magnet (PM) and the eccentricity were considered. Farhad Rezaee-Alam has calculated and analyzed the UMF in eccentric surface-mounted permanent-magnet motors under various eccentricity conditions (Rezaee-Alam et al., 2016). In this paper, the UMF is utilized as an excitation force in order to measure the dynamic characteristics of a turbomachine.

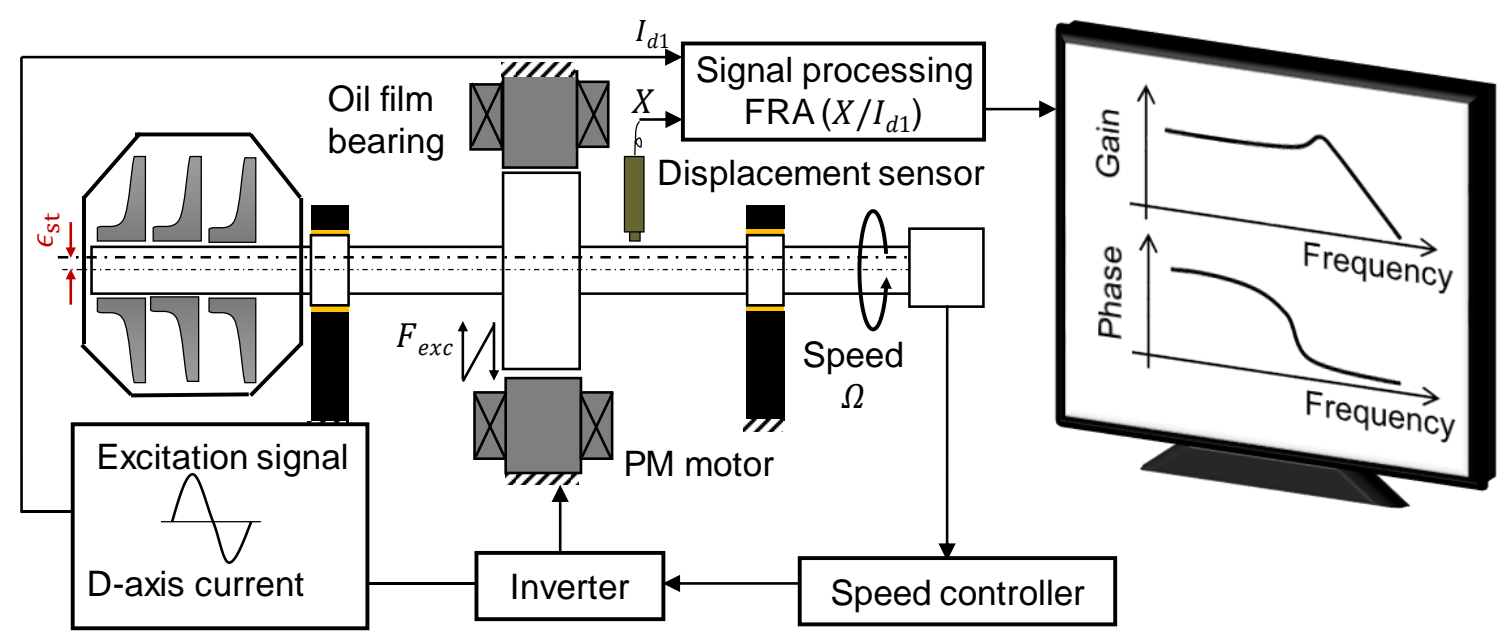

Fig. 1 Concept of proposed excitation method for rotor with a PM motor.

We propose utilizing electromagnetic excitation in order to make FRF measurements as shown in Fig. 1. Although various types of built-in motors are used to drive turbomachinery, in this method, we assume the built-in motor to be a permanent magnet (PM) synchronous motor. In general, direct-current (DC) added to the d-axis is usually used for fluxweakening control (Mwasilu et al., 2016; Nguyen et al., 2013; Liu et al., 2018). We assume the PM motor has static eccentricity. An alternating-current (AC) is injected into the d-axis to generate a sinusoidal radial excitation force, which causes the PM bias magnetic flux (Zhang and Foo, 2015) between the stator and rotor core to vary, leading to changes in the UMF in the PM motor. The varying UMF causes the rotor to vibrate in the radial direction. By measuring the displacement signal using displacement sensors, while sweeping the d-axis current, the FRFs can be obtained. This method has some advantages. First, the cost can be reduced and the mechanical components, except the non-contact displacement sensors, can be maintained. Second, the method is safe and effective. To verify our proposed method under various experimental conditions, a test rig with a bearingless motor (BELM) having motor windings and suspension windings was used. The proposed method was verified by comparing the FRFs measured using the motor winding with reference FRFs measured using the suspension windings. Rotor centricity is mainly divided into static and dynamic eccentricity. In previous research (Tsunoda et al., 2018, 2019b), we discussed measurement of the FRF of a rotor system with dynamic eccentricity. The effect of the eccentricity and the rotational speed on the FRF was not evaluated.

In the study reported in this paper, we made FRF measurements of a rotor system with static eccentricity. The rest of this paper is organized into five sections. Section 2 introduces the principle of the proposed method, and we carry out a theoretical analysis of the radial excitation force generated when using a rotor with static eccentricity. Section 3 presents the experimental setup. Section 4 describes the experimental method including simulation of the rotation of a rotor with static eccentricity and FRF measurements under various experimental conditions. Section 5 summarizes the results of the proposed method under the various test conditions and further discusses the proposed method. Section 6 gives the conclusions. 


\section{Nomenclature}

\begin{tabular}{|c|c|c|c|}
\hline$A$ & Constant of fitted gain curve & $B_{i}$ & Magnetic flux density in each section \\
\hline$c$ & Bearing damping coefficient & $f_{n}$ & Natural frequency of rotor system \\
\hline$F_{d}$ & $\begin{array}{l}\text { Magnetic motive force induced by the d-axis } \\
\text { current }\end{array}$ & $F_{i}$ & $\begin{array}{l}\text { Attractive force induced by the motor in each } \\
\text { section }\end{array}$ \\
\hline$F_{\text {motor_x }}$ & Attractive force in the $\mathrm{x}$-direction & $F_{m o t o r \_} y$ & Attractive force in the $y$-direction \\
\hline$F_{p m}$ & $\begin{array}{l}\text { Magnetic motive force induced by the } \\
\text { permanent magnet }\end{array}$ & $F_{x}$ & Radial force in the $\mathrm{x}$-direction \\
\hline$F_{y}$ & Radial force in the y-direction & $g$ & Air gap for a rotor with static eccentricity \\
\hline$g_{0}$ & Nominal air gap & $I_{d}$ & d-axis current \\
\hline$I_{d 0}$ & Bias d-axis current & $I_{d 1}$ & d-axis current amplitude \\
\hline$I_{\text {exc }}$ & Excitation current in suspension winding & $I_{\text {sus }}$ & $\begin{array}{l}\text { Amplitude of excitation current in suspension } \\
\text { winding }\end{array}$ \\
\hline$I_{q}$ & q-axis current & $i_{x}$ & $\begin{array}{l}\text { Current in the suspension winding in the } \mathrm{x} \text { - } \\
\text { direction }\end{array}$ \\
\hline$i_{y}$ & $\begin{array}{l}\text { Current in the suspension winding in the y- } \\
\text { direction }\end{array}$ & $I_{x r e f}$ & $\begin{array}{l}\text { Reference current in suspension winding in } \\
\text { the } \mathrm{x} \text {-direction }\end{array}$ \\
\hline$I_{y r e f}$ & $\begin{array}{l}\text { Reference current in suspension winding in } \\
\text { the y-direction }\end{array}$ & $I_{2 u}$ & U-phase suspension current \\
\hline$I_{2 v}$ & V-phase suspension current & $I_{2 w}$ & W-phase suspension current \\
\hline$I_{2 u r e f}$ & U-phase suspension reference current & $I_{2 v r e f}$ & V-phase suspension reference current \\
\hline$I_{2 w r e f}$ & W-phase suspension reference current & $I_{8 v}$ & V-phase motor current \\
\hline$I_{8 u}$ & U-phase motor current & $I_{8 w}$ & W-phase motor current \\
\hline$I_{8 v r e f}$ & V-phase motor reference current & $I_{8 u r e f}$ & U-phase motor reference current \\
\hline$I_{8 w r e f}$ & W-phase motor reference current & $k$ & Bearing stiffness \\
\hline$k_{d}$ & $\begin{array}{l}\text { Eccentricity-current-force coefficient of motor } \\
\text { winding }\end{array}$ & $k_{i}$ & $\begin{array}{l}\text { Current-force coefficient of suspension } \\
\text { winding }\end{array}$ \\
\hline$k_{s}$ & Stiffness of suspension winding & $k_{w}$ & Stiffness of motor winding \\
\hline$L$ & Rotor length & $L_{p m}$ & Thickness of the permanent magnet \\
\hline$m$ & Rotor mass & $N_{d}$ & Number of turns in the d-axis winding \\
\hline$P_{i}$ & Permeance in each section & $R$ & Rotor radius \\
\hline$R_{i}$ & $\begin{array}{l}\text { Magnetic resistance of the air gap in } \\
\text { each section }\end{array}$ & $R_{p m}$ & Magnetic resistance of each permanent magnet \\
\hline$t$ & Time & $v$ & Angular frequency of the excitation current \\
\hline$X_{\text {ref }}$ & Reference position in the $\mathrm{x}$-direction & $x$ & $\begin{array}{l}\text { Radial displacement of the rotor in the } \mathrm{x} \text { - } \\
\text { direction }\end{array}$ \\
\hline$Y_{\text {ref }}$ & Reference position in the $y$-direction & $y$ & $\begin{array}{l}\text { Radial displacement of the rotor in the } y- \\
\text { direction }\end{array}$ \\
\hline$\epsilon$ & Static rotor eccentricity in the $\mathrm{x}$-direction & $\epsilon_{1}$ & Rotor deformation \\
\hline$\epsilon_{0}$ & Initial rotor eccentricity & $\epsilon_{s t}$ & $\begin{array}{l}\text { Static rotor eccentricity in the bearingless } \\
\text { motor }\end{array}$ \\
\hline$\epsilon_{a m p}$ & Oscillation amplitude & $\zeta$ & Damping ratio of rotor system \\
\hline$\theta$ & $\begin{array}{l}\text { Initial angle between the centerline of one pair } \\
\text { of PMs and } \mathrm{x} \text {-axis }\end{array}$ & $\mu_{0}$ & Permeability of air gap \\
\hline$\mu_{\mathrm{pm}}$ & Permeability of the permanent magnet & $\phi$ & Absolute angle \\
\hline$\phi_{0}$ & Rotational angle & $\phi_{m}$ & Oscillation phase \\
\hline
\end{tabular}



$\psi_{i} \quad$ Magnetic flux in the air gap in each section
$\Omega \quad$ Rotational speed
$\Omega_{\text {ref }} \quad$ Reference rotational speed
$\omega_{n} \quad$ Natural angular frequency of rotor system

\section{Theoretical analysis of the excitation force for a rotor with static eccentricity}

\subsection{Model for radial motion of a rigid spindle with static eccentricity}

The equation of radial motion of a rigid rotor supported by elastic bearings can be expressed by Eq. (1):

$$
\left\{\begin{array}{l}
m \ddot{x}+c \dot{x}+k x=F_{x} \\
m \ddot{y}+c \dot{y}+k y=F_{y}
\end{array}\right.
$$

where $m, k$, and $c$ are the mass, stiffness and damping coefficient, respectively, $x$ and $y$ are the radial displacements of the rotor in the $\mathrm{x}$ - and $\mathrm{y}$-directions, respectively. The supporting stiffness and damping are isotropic in the radial direction. $F_{x}$ and $F_{y}$ are the radial forces. The rigid rotor is assumed to rotate with static eccentricity.

\subsection{Generation of radial excitation force}

In the proposed method, an $\mathrm{AC}$ current is injected into the d-axis of the motor to generate a radial excitation force. The bias magnetic flux generated by the PMs is changed by the DC d-axis current to extend the speed range. A consequent-pole-type motor with four PMs is used in the rotor system. Figure 2 shows a cross-sectional view of the rotor, which has static eccentricity $\epsilon$ in the x-direction. The black lines show the magnetic flux from the PMs and the red lines show the magnetic flux from the motor windings. As shown in Fig. 3, the line between the centers of one pair of PMs has an initial angle $\theta$ with respect to the x-axis. The rotational angle $\phi_{0}$ is obtained from the product of the rotational speed $\Omega$ and time $t$. The absolute angle $\phi$ is obtained by adding these together, as in the following equation:

$$
\phi=\phi_{0}+\theta
$$

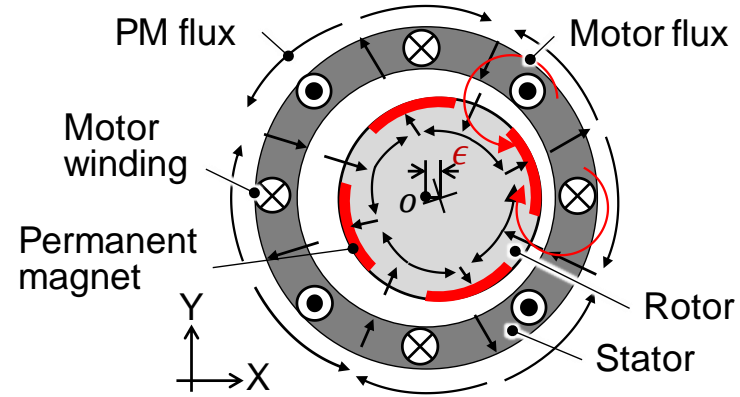

Fig. 2 Cross-sectional view of a consequent-poletype motor with static eccentricity and the magnetic flux path from the PMs and the motor windings.

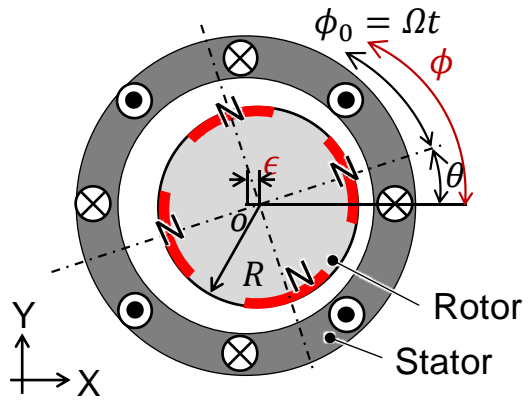

Fig. 3 The angular relationship between the absolute, rotational, and initial angles.

As shown in Fig. 4, the motor model is divided into eight 45-degree sections, and the sections are labeled in turn in the counterclockwise direction. We assume that the magnetic flux is uniformly distributed within each section. In each section, the magnetic resistance of the air gap between the stator and rotor core is $R_{i}(i=1,2, \ldots, 8)$, the magnetic flux in the air gap is $\psi_{i}$, and the attractive force induced by the motor is $F_{i}$. The magnetic resistance of each permanent magnet can be calculated from the following Eq. (3):

$$
R_{p m}=4 L_{p m} /\left(\mu_{p m} R L \pi\right)
$$

where $L_{p m}$ and $\mu_{\mathrm{pm}}$ are the thickness and permeability of the permanent magnet, respectively. $R$ and $L$ are the radius 
and length of the rotor, respectively.

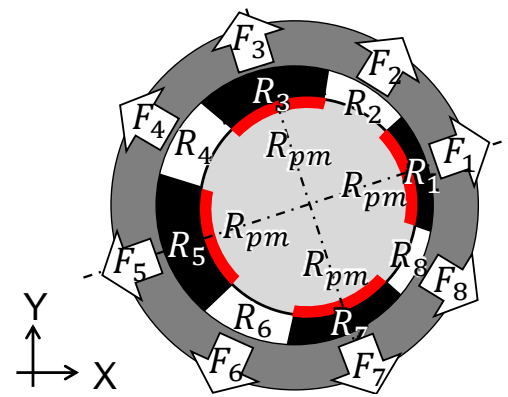

Fig. 4 The magnetic resistance and unbalanced magnetic force divided into eight sections.

The air gap for a rotor with static eccentricity is given by Eq. (4):

$$
g=g_{0}\left\{1-\frac{\epsilon}{g_{0}} \cos \left(\theta+\phi_{0}\right)\right\}
$$

where $\epsilon$ is much smaller than the nominal air gap $g_{0}\left(1 \gg \epsilon / g_{0}\right)$. The permeance $P_{i}(i=1,2, \ldots, 8)$ in each section can be obtained from Eq. (5):

$$
P_{i}=\frac{\mu_{0} R L}{g_{0}} \int_{(-\pi / 8)+(i-1) \pi / 4}^{(\pi / 8)+(i-1) \pi / 4}\left\{1-\frac{\epsilon}{g_{0}} \cos \left(\theta+\phi_{0}\right)\right\} \mathrm{d} \theta \quad(i=1,2, \ldots, 8)
$$

Based on the magnetic flux path in Fig. 2, the equivalent magnetic circuit is obtained as shown in Fig. 5. $F_{p m}$ and $F_{d}\left(=N_{d} I_{d}\right)$ represent the magnetic motive force induced by the permanent magnet and the d-axis current, respectively. The magnetic flux $\psi_{i}(i=1,2, \ldots, 8)$ in the air gaps in the respective sections is given by Eq. (6):

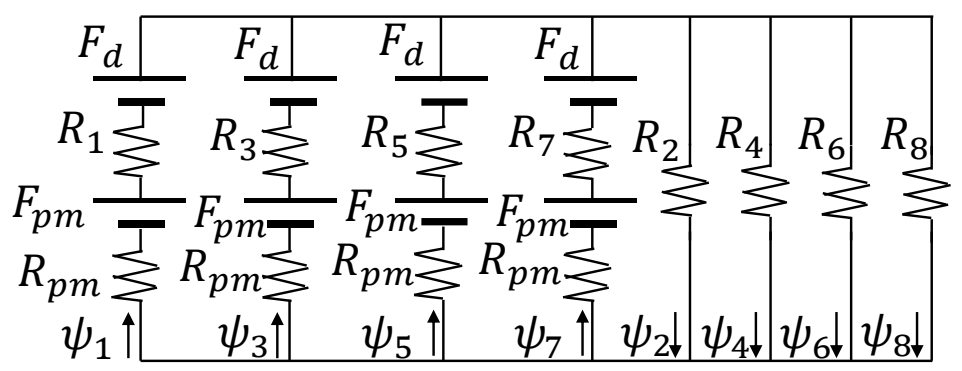

Fig. 5 The equivalent circuit for the magnetic flux path. 


$$
\left\{\begin{aligned}
\left(R_{1}+R_{p m}\right) \psi_{1} & =\left(R_{3}+R_{p m}\right) \psi_{3} \\
\left(R_{3}+R_{p m}\right) \psi_{3} & =\left(R_{5}+R_{p m}\right) \psi_{5} \\
\left(R_{5}+R_{p m}\right) \psi_{5} & =\left(R_{7}+R_{p m}\right) \psi_{7} \\
R_{2} \psi_{2} & =R_{4} \psi_{4} \\
R_{4} \psi_{4} & =R_{6} \psi_{6} \\
R_{6} \psi_{6} & =R_{8} \psi_{8} \\
F_{p m}+F_{d}-\left(R_{1}\right. & \left.+R_{p m}\right) \psi_{1}=R_{2} \psi_{2} \\
\psi_{1}+\psi_{3}+\psi_{5}+\psi_{7} & =\psi_{2}+\psi_{4}+\psi_{6}+\psi_{8}
\end{aligned}\right.
$$

The magnetic flux is divided by the area to obtain the magnetic flux density $B_{i}=\psi_{i} /(R L \pi / 4)$. The attractive force $F_{i}=(R L \pi / 4) B_{i}^{2} / \mu_{0}$ can be calculated utilizing the magnetic flux density. Finally, the attractive forces in the $\mathrm{x}-$ and $\mathrm{y}-$ directions $\left(F_{\text {motor_x }}, F_{\text {motor_y }}\right)$ can be obtained from the following equations:

$$
\left\{\begin{array}{l}
F_{\text {motor }}=\sum_{i=1}^{8} F_{i} \cos \left\{\frac{\pi}{4}(i-1)+\phi_{0}\right\} \\
F_{\text {motor }}=\sum_{i=1}^{8} F_{i} \sin \left\{\frac{\pi}{4}(i-1)+\phi_{0}\right\}
\end{array}\right.
$$

The above calculation is performed using Mathematica ${ }^{\circledR}$ and an analytical solution for the attractive forces in the $\mathrm{x}$ and y-directions can be obtained using Eq. (8):

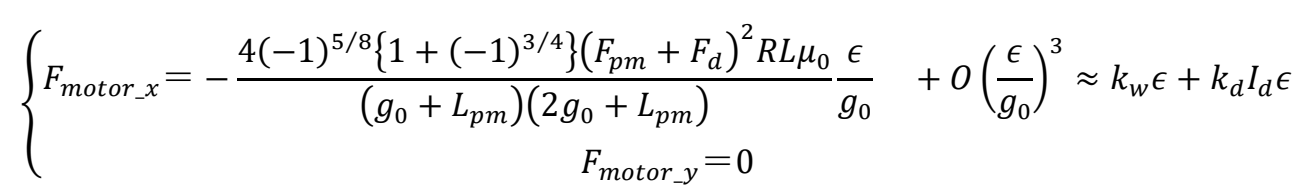

where $k_{w}$ and $k_{d}$ are the initial negative stiffness and the eccentricity-current-force coefficient, respectively. $O\left(\frac{\epsilon}{g_{0}}\right)^{3}$ can be ignored. In this case, since $\phi_{0}$ is not in the above equation, the attractive force is independent of the rotational angle of the rotor. Since $F_{p m} \gg F_{d}=N_{d} I_{d}$, the formula can be simplified into a linear relationship.

\subsection{Motor radial force model}

With a static eccentricity $\epsilon$ in the x-direction, the attractive force in the y-direction is zero and the equation of motion in the $\mathrm{x}$-direction is given by Eq. (9)

$$
m \ddot{x}+c \dot{x}+k x=F_{\text {motor_}} x
$$

The center of the stator is set as the origin of the coordinates. When the initial eccentricity of the rotor in the $\mathrm{x}$ direction is $\epsilon_{0}$, the rotor has a small deformation $\epsilon_{1}$ that generates a restoring force that balances the attractive force induced by the motor, which is given by Eq. (10):

$$
k \epsilon_{1}=k_{w} \epsilon+k_{d} I_{d} \epsilon
$$

where $\epsilon$ is the static eccentricity, which is equal to the sum of the initial eccentricity $\epsilon_{0}$ and the deformation of the rotor $\epsilon_{1}$ as shown in Fig. 6. 


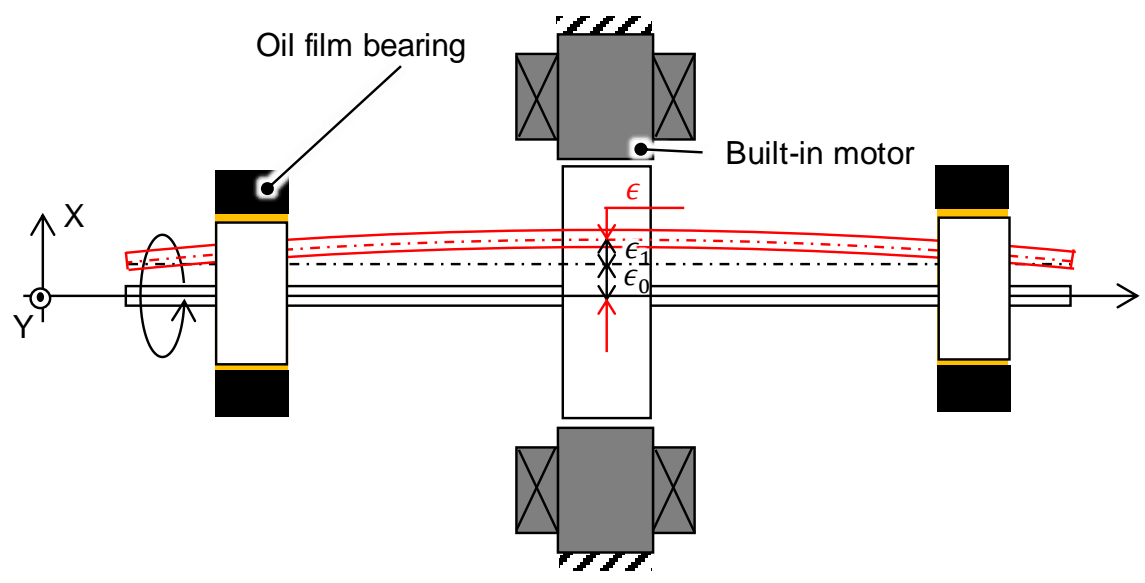

Fig. 6 Eccentricities of the rotor supported by two bearings

We assumed that the displacement of the rotor from the initial eccentricity $\epsilon_{0}$ is $x=\epsilon_{1}+\Delta x$ and the d-axis current is $I_{d}=I_{d 0}+I_{d 1} \cos v t$, in which the $\mathrm{AC}$ component excites the vibration. The displacement, attractive force, and d-axis current can be combined with Eqs. (9) and (10) resulting in the following equation of motion:

$$
m\left(\epsilon_{1} \ddot{+} \Delta x\right)+c\left(\epsilon_{1} \dot{+} \Delta x\right)+k\left(\epsilon_{1}+\Delta x\right)=k_{w}(\epsilon+\Delta x)+k_{d} I_{d 0}(\epsilon+\Delta x)+k_{d} I_{d 1}(\epsilon+\Delta x) \cos v t
$$

Since $k_{w} \gg k_{d} I_{d 0}$ and $\epsilon \gg \Delta x$, the motor radial force model can be simplified to Eq. (12) by substituting Eq. (10) into Eq. (11):

$$
m \ddot{\Delta x}+c \dot{\Delta x}+\left(k-k_{w}\right) \Delta x=k_{d} I_{d 1} \epsilon \cos v t
$$

This equation describes the dynamic model of the rigid rotor and we can define the excitation force as $F_{\text {exc }}=$ $k_{d} I_{d 1} \in \cos v t$. The excitation force can be controlled by the d-axis current.

\section{Experimental test rig}

\subsection{Test rig with a bearingless motor}

A compact and simple test rig with a BELM was used as shown in Fig. 7 (Tsunoda et al., 2019a, 2019b). The rotor is supported by two circular oil-film bearings and rotated by a consequent-pole-type BELM (Chiba et al. 2005) placed at the midpoint of the rotor-shaft. The oil viscosity is $49 \mathrm{mPa} \cdot \mathrm{s}$ and the $1^{\text {st }}$ bending frequency of the rotor-shaft is $42 \mathrm{~Hz}$. Table 1 shows the dimensions of the test rig. Displacement sensors (PU-05, Applied electronics Crop.) are mounted symmetrically on both sides of the BELM in the $\mathrm{x}$ - and y-directions. A non-contact encoder is placed at the end of the rotor-shaft to detect the rotational speed and angle. To avoid any rotor-stator contact during magnetic suspension, two touchdown bearings made of polyacetal are located on both sides of the BELM. Figure 8 shows a cross-sectional view of the consequent-pole-type BELM, which has motor windings and suspension windings in one stator. Table 2 summarizes the dimensions of the BELM. The motor windings, which are three phase and have eight poles, are used for rotation. The suspension windings are three phase and have two poles, and are used for positioning the rotor. Table 3 shows the configurations and characteristics of the two types of windings. 


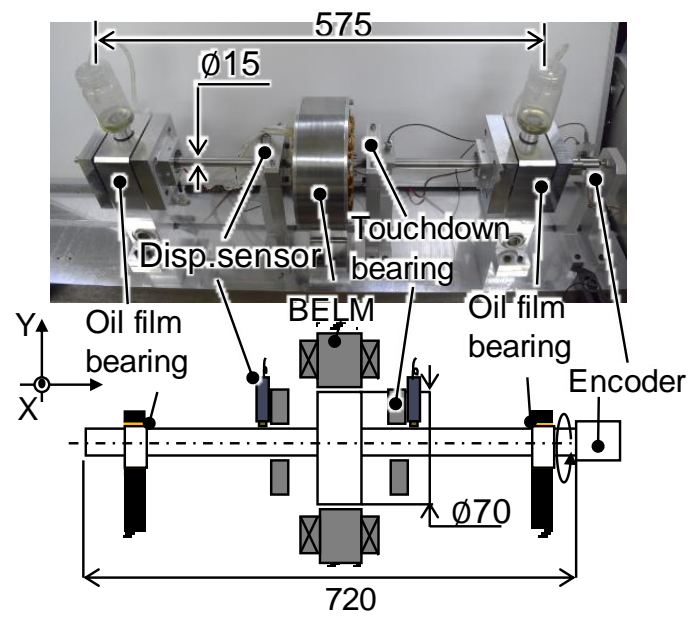

Fig. 7 Photograph and configuration of the test rig.

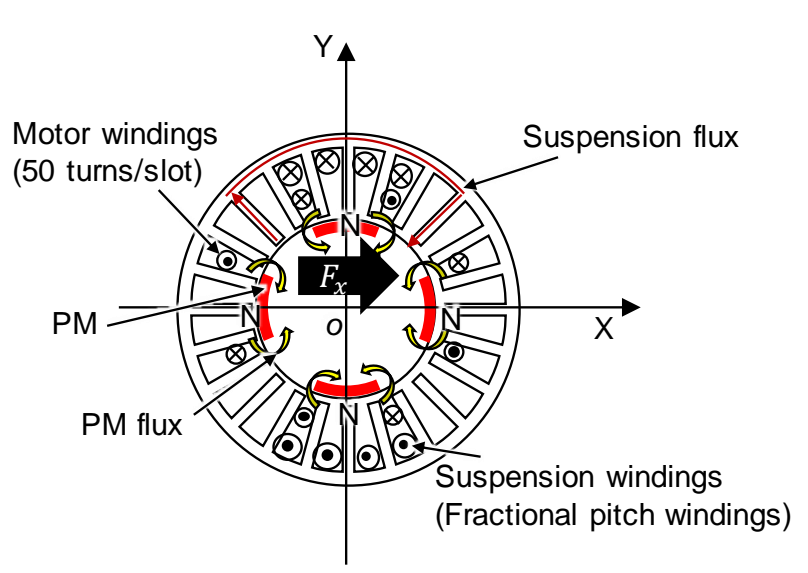

Fig. 8 Cross-sectional view of the consequent poletype BELM (The U-phase suspension windings and motor windings are illustrated. The suspension flux is indicated by red lines).

As illustrated in Fig. 8, The radial force can be generated by the flux from the suspension windings, which can strengthen or weaken the bias magnetic fluxes on both the right and left hand sides. Therefore, the position of the rotor can be controlled by the current in the suspension windings. In previous simulations and experiments (Tsunoda et al., 2017b), the radial forces in the $\mathrm{x}$ - and $\mathrm{y}$-directions were measured. These can be expressed by the following equations:

$$
\left\{\begin{array}{l}
F_{x}=k_{i} i_{x}-k_{s} x \\
F_{y}=k_{i} i_{y}-k_{s} y
\end{array}\right.
$$

where $k_{i}=27.0 \mathrm{~N} / \mathrm{A}$ and $k_{\mathrm{s}}=-971 \mathrm{~N} / \mathrm{mm}$ are the current-force coefficient and the negative stiffness, respectively. $i_{x}$ and $i_{y}$ are the currents in the suspension winding in the $\mathrm{x}$ - and $\mathrm{y}$-directions. $x$ and $y$ are the displacements of the rotor in the $\mathrm{x}$ - and $\mathrm{y}$-directions.

Table 1 Dimensions of test rig.

\begin{tabular}{|c|c|c|c|}
\hline \hline \multicolumn{2}{|c|}{ Rotor } & \multicolumn{2}{c|}{ Oil-film bearing } \\
\hline Mass & $2.6[\mathrm{~kg}]$ & Diameter & $25[\mathrm{~mm}]$ \\
\hline Diameter & $15[\mathrm{~mm}]$ & Clearance & $0.1[\mathrm{~mm}]$ \\
\hline Length & $720[\mathrm{~mm}]$ & Length & $25[\mathrm{~mm}]$ \\
\hline
\end{tabular}

Table 2 Dimensions of consequent-pole-type BELM.

\begin{tabular}{|c|c|c|c|}
\hline \hline Rotor diameter & $70[\mathrm{~mm}]$ & PM outer diameter & $69[\mathrm{~mm}]$ \\
\hline Stator diameter & $160[\mathrm{~mm}]$ & PM thickness & $5[\mathrm{~mm}]$ \\
\hline Clearance & $1[\mathrm{~mm}]$ & PM arc & $45\left[{ }^{\circ}\right]$ \\
\hline Length & $50[\mathrm{~mm}]$ & Length of teeth & $29[\mathrm{~mm}]$ \\
\hline Slot number & 24 & Teeth width & $4.8[\mathrm{~mm}]$ \\
\hline
\end{tabular}

\subsection{Suspension and rotation control systems}

Proportional-integral-derivative (PID) controllers were used in the suspension control system. The values of the PID parameters were tuned experimentally. Figure 9 shows the suspension control system. The reference currents $I_{x r e f}$ and 
$I_{\text {yref }}$ are outputted from the PID controller. These are transformed from two-phase into three-phase currents $I_{2 u r e f}, I_{2 v r e f}$, and $I_{2 w r e f}$, and then inputted into three current amplifiers to generate the radial force on the BELM. These controls are carried out using a DSP system (MicroLabBox, dSPACE, GmbH.) with a sampling frequency of 20 kHz. Three PWM single-phase amplifiers (Junus JSP-180-20, Copley Controls Corp.) are used for the suspension control system and the bandwidth of current feedback system $I_{2 u} / I_{2 u r e f}$ is about $600 \mathrm{~Hz}$.

Table 3 Configurations of windings and characteristics of BELM.

\begin{tabular}{|c|c|c|}
\hline \hline The design of coils & Copper, $\varnothing 0.8 \mathrm{~mm}$, Max. current 5 A \\
\hline \multirow{3}{*}{ Motor windings } & Parallel wires & 2 \\
\cline { 2 - 3 } & Series turns per slot & 25 \\
\cline { 2 - 3 } & Average eccentricity-current-force coefficient $k_{d}$ & $18.5[\mathrm{~N} / \mathrm{A} \cdot \mathrm{mm}]$ \\
\hline \multirow{3}{*}{$\begin{array}{c}\text { Suspension } \\
\text { windings }\end{array}$} & Single wire & 1 \\
\cline { 2 - 3 } & Series turns per slot & 10 \\
\cline { 2 - 3 } & Current-force coefficient $k_{i}$ & $-971[\mathrm{~N} / \mathrm{mm}]$ \\
\hline
\end{tabular}

Figure 10 shows the rotational control system. A PI controller is used and the coordinates are transformed from direct-quadrature to three-phase to control the rotational speed. The absolute rotor angle is measured by the non-contact encoder and the rotational speed $\Omega$ is calculated using a frequency-to-voltage (FV) converter through the sawtooth wave of the rotor angle. The differences between the reference rotational speed $\Omega_{\text {ref }}$ and the measured rotational speed $\Omega$ is inputted into the PI controller and the amplitude of the q-axis current $I_{q}$ is calculated by the PI controller, whose parameters are $0.5 \mathrm{~A} / \mathrm{rps}$ for the proportional gain and $0.5 \mathrm{~A} / \mathrm{rps}^{\cdot} \mathrm{s}$ for the integral gain. $I_{q}$ and $I_{d}$ are transformed to three-phase reference currents and the motor currents $I_{8 u}, I_{8 v}$ and $I_{8 w}$ act on the motor windings to generate the motor torque through the amplifiers. The same DSP system used for the suspension control system is applied. Current amplifiers (7425 AC, Copley Controls Corp.) are used and the bandwidth of the current feedback system $I_{8 u} / I_{8 u r e f}$ is approximately $1000 \mathrm{~Hz}$.

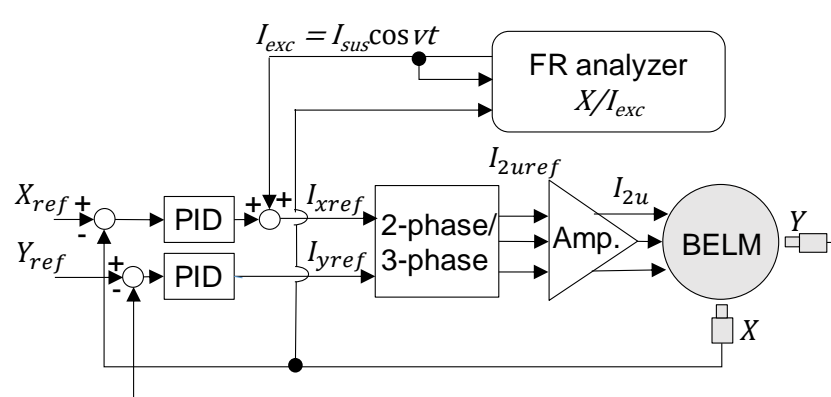

Fig. 9 Block diagram for the suspension control system and configuration of the FRF measurement using the suspension windings.

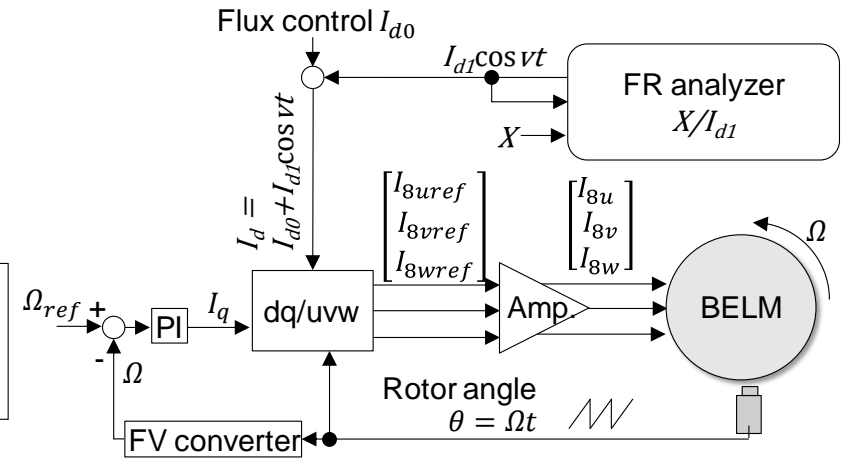

Fig. 10 Block diagram for the rotational control system and configuration of the FRF measurement using the motor windings.

\section{Experimental method}

\subsection{Realization of rotation with static eccentricity}

\subsubsection{Motor center}

In this experiment, the center of the motor is defined when the DC current through the suspension windings is zero. The static eccentricity of the rotor is defined utilizing the distance and direction from the motor center. To find the center of the motor, the zero-power controller was used by first setting the reference position $X_{\text {ref }}$ and $Y_{\text {ref }}$ to $(0 \mu \mathrm{m}, 0 \mu \mathrm{m})$. 
Due to the roundness error of the rotor, the position of the motor center depends on the rotational angle. Therefore, the average position $(-20 \mu \mathrm{m}, 70 \mu \mathrm{m})$ during the rotation is defined as the motor center.

\subsubsection{Elimination of whirling}

When the rotor rotates at a speed of $40 \mathrm{rps}$, the amplitude of whirling is approximately $95 \mu \mathrm{m}$. To eliminate this, the reference positions in the suspension control system were sinusoidally changed synchronously with the rotation to generate a radial force to counteract the unbalanced force (Tsunoda et al., 2017b, 2019a). Furthermore, the static eccentricity $\epsilon_{s t}$ was added to the reference positions in the suspension control system as follows:

$$
\left\{\begin{array}{c}
X_{r e f}=\epsilon_{a m p} \cos \left(\Omega t+\phi_{m}\right)+\epsilon_{s t} \\
Y_{\text {ref }}=\epsilon_{a m p} \sin \left(\Omega t+\phi_{m}\right)
\end{array}\right.
$$

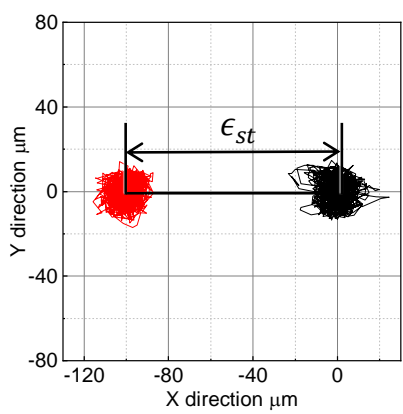

Fig. 11 Simulation of the static eccentricity rotation.

Note that $\epsilon_{a m p}$ is the amplitude of the oscillation and $\Omega$ is the rotational speed, and $\phi_{m}$ is the phase, which depends on the position of the center of mass. Figure 11 shows the amplitude of whirling is reduced to $20 \mu \mathrm{m}$ and the static eccentricity rotation is fixed at $100 \mu \mathrm{m}$

\subsection{FRF measurement using the suspension windings and the motor windings}

\subsubsection{FRFs measured utilizing the suspension windings}

To verify the proposed method, FRF measurements utilizing the radial excitation force generated by the suspension windings of the BELM were used as a reference. Figure 9 shows the configuration of the FRF measurements using the suspension windings. The excitation current $I_{\text {exc }}=I_{\text {sus }} \cos v t$ from a frequency response (FR) analyzer (FRA5022, NF Corp.) was inputted into the reference current in the x-direction, where $I_{\text {sus }}$ is the amplitude of the excitation current in the suspension windings and $v$ is the angular frequency of the excitation current. The amplitude of excitation current $I_{\text {sus }}$ was set to $0.5 \mathrm{~A}$. The FRFs from the excitation current $I_{\text {sus }}$ to the displacement of the rotor were measured by a FR analyzer from $1 \mathrm{~Hz}$ to $300 \mathrm{~Hz}$ during rotation.

\subsubsection{FRFs measured utilizing motor windings}

Figure 10 shows the configuration of the FRF measurement using the motor windings. An AC current signal of $I_{d 1} \cos v t$ from the FR analyzer was added to the d-axis current $I_{d}$. During rotation, the d-axis current was as follows:

$$
I_{d}=I_{d 0}+I_{d 1} \cos v t
$$

Note that $I_{d 0}$ is the bias d-axis current for flux control during rotation and the value of the bias d-axis current depends on the rotational speed due to the flux-weakening control. $I_{d 1}$ is the amplitude of the excitation current, which was set to $2.5 \mathrm{~A}$. The FRFs from the current command $I_{d 1}$ to the displacement of the rotor were also measured by the FR analyzer.

\subsection{Test conditions}

To more completely verify the feasibility of the proposed method, some of the rotational conditions, such as the 
eccentricity and rotational speed, were varied. Furthermore, the rotor dynamics were also changed by tuning the PID parameters of the BELM controller. In these experiments, three sets of the PID controller parameters were implemented as shown in Table 4. The controller parameters were different in the $\mathrm{x}$ - and y-directions to ensure the same closed-loop in both directions due to the position of the levitation having a non-uniform air gap, with the zero-power controller used to balance the force due to gravity. In the PID controller, parameters 1, 2, and 3 had the highest, middle and lowest derivative gains, respectively, to simulate the changes in the dynamic characteristics of the rotor system. The proportional and integral gains remain constant to set the natural frequency response of the first shaft bending mode at approximately 50-70 Hz.

Table 4 PID controller parameters.

\begin{tabular}{|c|c|c|c|c|}
\hline \hline \multicolumn{2}{|c|}{} & $\begin{array}{c}\text { Parameter 1 } \\
(\text { High })\end{array}$ & $\begin{array}{c}\text { Parameter 2 } \\
\text { (Medium) }\end{array}$ & $\begin{array}{c}\text { Parameter 3 } \\
(\text { Low })\end{array}$ \\
\hline \multirow{3}{*}{ X-direction } & $K_{p}[\mathrm{~A} / \mathrm{m}]$ & \multicolumn{3}{|c|}{40,000} \\
\cline { 2 - 5 } & $K_{i}[\mathrm{~A} / \mathrm{m} \cdot \mathrm{s}]$ & \multicolumn{3}{|c|}{13,100} \\
\cline { 2 - 5 } Y-direction & $K_{d}[\mathrm{~A} \cdot \mathrm{s} / \mathrm{m}]$ & 52 & 36 & 20 \\
\hline & $K_{p}[\mathrm{~A} / \mathrm{m}]$ & & 53,000 \\
\cline { 2 - 6 } & $K_{i}[\mathrm{~A} / \mathrm{m} \cdot \mathrm{s}]$ & & 17,700 \\
& $K_{d}[\mathrm{~A} \cdot \mathrm{s} / \mathrm{m}]$ & 60 & 43 & 25 \\
\hline
\end{tabular}

Table 5 lists the experimental eccentricities and rotational speeds. As shown in Eq. (12), the excitation force is proportional to the eccentricity and the eccentricities of rotational machines are different due to imprecise nature of assembly. Thus, the effect of eccentricity on the measurement accuracy of the FRF was tested. The values of the static eccentricities were set to $100 \mu \mathrm{m}, 50 \mu \mathrm{m}$, and $25 \mu \mathrm{m}$ in the negative x-direction, respectively.

The dynamic characteristics of the rotor system also depend on the rotational speed due to the stiffness and damping variation of the oil-film bearings. The effect of the rotational speed on the proposed method needs to be considered. The rotational speed in our experiments was set to $40 \mathrm{rps}, 30 \mathrm{rps}$, and $20 \mathrm{rps}$ and the $I_{d 0}$ bias d-axis current was set to -4.5 $\mathrm{A},-2.5 \mathrm{~A}$, and $-2.0 \mathrm{~A}$, respectively.

Table 5 Experimental eccentricities and rotational speeds.

\begin{tabular}{|c|c|}
\hline \hline \multirow{2}{*}{ Eccentricities $[\mu \mathrm{m}]$} & 100 \\
& 50 \\
\hline \multirow{2}{*}{ Rotational speeds $[\mathrm{rps}]$} & 25 \\
\hline & 30 \\
\hline & 20 \\
\hline
\end{tabular}

\section{Experimental results}

\subsection{Electromagnetic excitation}

Various rotational speeds, eccentricities, and rotor dynamics were changed in the experiments. Figure 12 shows the waveform of a typical experiment utilizing the motor windings. The rotational speed was set to 40 rps and the static eccentricity $\epsilon_{s t}$ was fixed as $100 \mu \mathrm{m}$ in the negative x-direction. The offset of the d-axis current $I_{d 0}$ and the amplitude of the d-axis current $I_{d 1}$ were set to $-4.5 \mathrm{~A}$ and $2.5 \mathrm{~A}$, respectively. Parameter 3 , having a low damping ratio, was chosen due to the obvious peak of the natural frequency. With an eccentricity of $100 \mu \mathrm{m}$ in the negative $\mathrm{x}$-direction and excitation signal at $1 \mathrm{~Hz}$, the amplitude of the rotor calculated utilizing a FFT at $1 \mathrm{~Hz}$ was $9.7 \mu \mathrm{m}$. The average q-axis current used to generate the torque was $0.68 \mathrm{~A}$. The measured rotational speed had an error of $1 \mathrm{rps}$ and $0.1 \mathrm{rps}$ with and without excitation, respectively. 

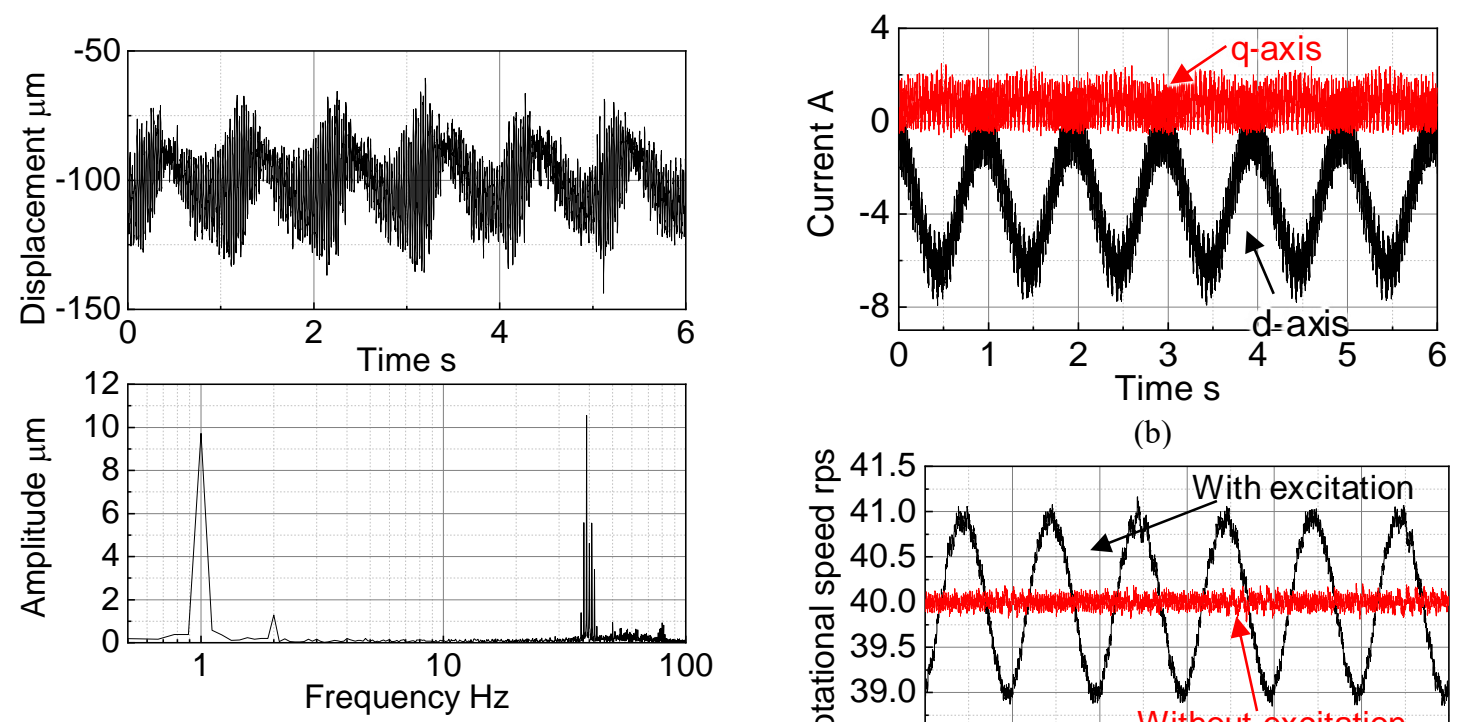

(b)

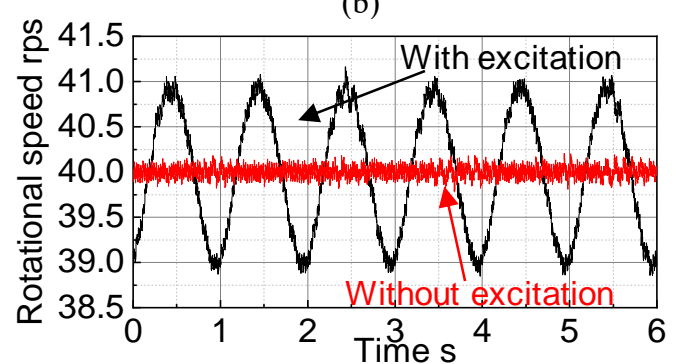

(c)

Fig. 12 (a) Waveform of displacement and FFT analysis of displacement in the negative x-direction at $1 \mathrm{~Hz}$ excitation in a typical experiment. (b) Motor current at $1 \mathrm{~Hz}$ excitation in a typical experiment. (c) Rotational speed with and without $1 \mathrm{~Hz}$ excitation in a typical experiment.

\subsection{FRF measurement}

\subsubsection{Effect of rotor dynamics}

Figure 13 shows the measured gain plots of the FRFs with different PID parameters and fitted lines from $1 \mathrm{~Hz}$ to 300 $\mathrm{Hz}$ under typical experimental conditions. The unit of gain is $\mathrm{mm} / \mathrm{A}$. The red and black lines were measured utilizing excitation forces generated by the motor windings and the suspension windings, respectively, and the three pairs of red and black gain curves are similar, except for an offset of $20 \mathrm{~dB}$ owing to the different current-force coefficients. The gain curves, shown by the blue lines, have been fitted utilizing the least squares method to the measured curves using Eq. (16):

$$
G_{p}(s)=\frac{A}{s^{2}+2 \zeta \omega_{n} s+\omega_{n}{ }^{2}}
$$

Note that $A$ is a constant, $\zeta$ is the damping ratio, and $\omega_{n}$ is the natural angular frequency, respectively. The natural frequency $f_{n}$ is obtained as $f_{n}=\omega_{n} / 2 \pi$.

Table 6 lists the identified damping ratio, natural frequency, and the percentage differences in the values obtained using the motor windings compared to those obtained using the suspension windings. The difference between the identified natural frequencies and the difference between the damping ratios for the two different FRFs are less than 5.2\%, proving the validity of the proposed method. 


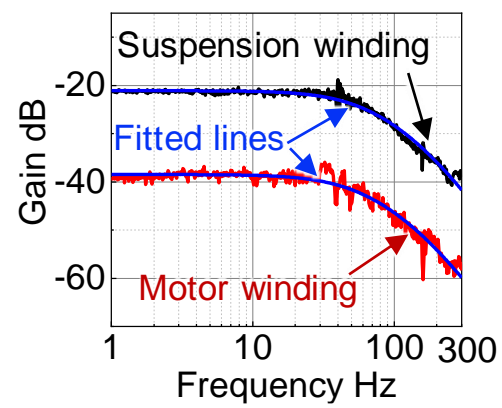

(a) Parameter 1 (High damping).

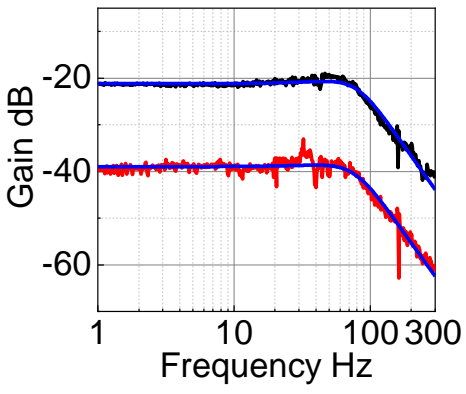

(b) Parameter 2 (Medium damping).

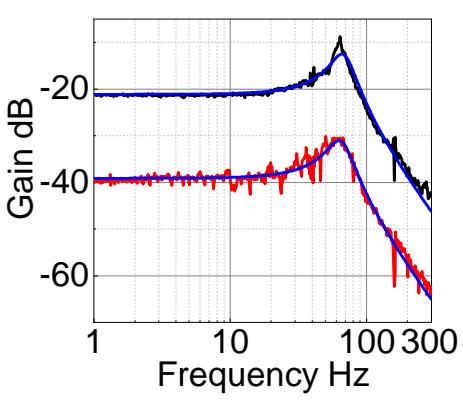

(c) Parameter 3 (Low damping).

Fig. 13 Measured FRFs with various rotor dynamics.

Table 6 Identified parameters and differences with various rotor dynamics.

\begin{tabular}{|c|c|c|c|c|}
\hline \hline & $\begin{array}{c}\text { Suspension } \\
\text { windings (standard) }\end{array}$ & $\begin{array}{c}\text { Motor } \\
\text { windings }\end{array}$ & $\begin{array}{c}\text { Differences } \\
(\%)\end{array}$ \\
\hline Parameter 1 & $f_{n}[\mathrm{~Hz}]$ & 99 & 95 & 4.0 \\
\cline { 2 - 5 } & $\zeta$ & 1.14 & 1.18 & 3.5 \\
\hline Parameter 2 & $f_{n}[\mathrm{~Hz}]$ & 80 & 77 & 3.8 \\
\cline { 2 - 6 } & $\zeta$ & 0.58 & 0.61 & 5.2 \\
\hline \multirow{2}{*}{ Parameter 3 } & $f_{n}[\mathrm{~Hz}]$ & 69 & 66 & 4.4 \\
\hline & $\zeta$ & 0.20 & 0.19 & 5.0 \\
\hline
\end{tabular}

\subsubsection{Effect of eccentricity}

Figure 14 illustrates the frequency responses from $1 \mathrm{~Hz}$ to $300 \mathrm{~Hz}$ and the results of the displacement in the $\mathrm{x}-$ direction with static eccentricities of $25 \mu \mathrm{m}, 50 \mu \mathrm{m}$, and $100 \mu \mathrm{m}$. The rotational speed was $40 \mathrm{rps}$, the bias d-axis current was $-4.5 \mathrm{~A}$ and the amplitude of the d-axis current was $2.5 \mathrm{~A}$. In Fig. 14 (a), the different offsets in the gain plots measured by the motor windings are a result of the different excitation forces caused by the different eccentricities. In Fig 14 (b), the amplitudes of displacement at $1 \mathrm{~Hz}$ are $4.3 \mu \mathrm{m}, 6.1 \mu \mathrm{m}$, and $9.7 \mu \mathrm{m}$ with the static eccentricities fixed at $25 \mu \mathrm{m}, 50$ $\mu \mathrm{m}$, and $100 \mu \mathrm{m}$, respectively, in which the eccentricity is positively correlated with the amplitude of the displacement. The peak at $40 \mathrm{~Hz}$ is due to the unbalanced vibration of the rotor at $40 \mathrm{rps}$. Table 7 summaries the identified natural frequencies, damping ratios, and percentage differences. The differences are less than $6.3 \%$. Therefore, even when the eccentricity is $25 \mu \mathrm{m}$, the FRF measurement can be achieved using the proposed method.

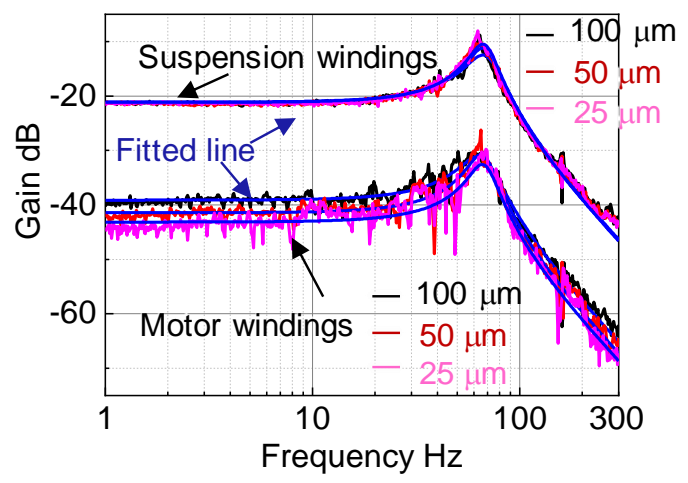

(a)

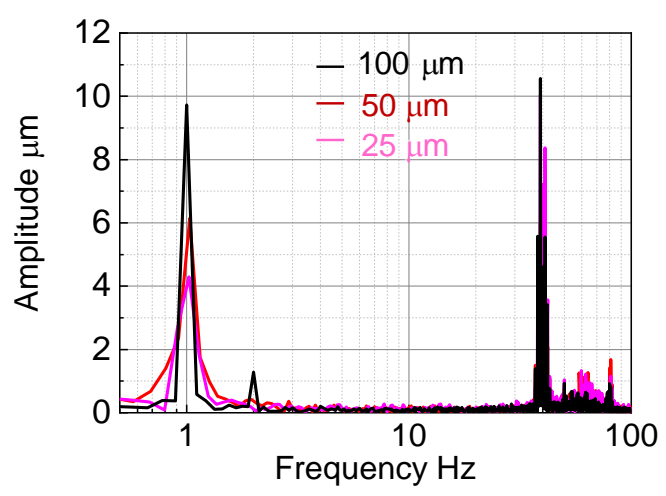

(b)

Fig. 14 (a) Frequency responses with different eccentricities at $25 \mu \mathrm{m}, 50 \mu \mathrm{m}$ and $100 \mu \mathrm{m}$ at a speed of $40 \mathrm{rps}$. (b) FFT analysis of rotor displacement with different eccentricities applying $1 \mathrm{~Hz}$ excitation at a speed of $40 \mathrm{rps}$. 
Yang, Tsunoda, Han, Zhong and Shinshi,

Journal of Advanced Mechanical Design, Systems, and Manufacturing, Vol.14, No.4 (2020)

Table 7 Identified parameters and differences with different eccentricities.

\begin{tabular}{|c|c|c|c|c|}
\hline \hline \multirow{2}{*}{2} & $\begin{array}{c}\text { Suspension } \\
\text { windings (standard) }\end{array}$ & $\begin{array}{c}\text { Motor } \\
\text { windings }\end{array}$ & $\begin{array}{c}\text { Differences } \\
(\%)\end{array}$ \\
\hline \multirow{2}{*}{$25 \mu \mathrm{m}$} & $f_{n}[\mathrm{~Hz}]$ & 69 & 66 & 4.4 \\
\cline { 2 - 5 } & $\zeta$ & 0.20 & 0.19 & 5.0 \\
\hline \multirow{2}{*}{$50 \mu \mathrm{m}$} & $f_{n}[\mathrm{~Hz}]$ & 68 & 66 & 2.9 \\
\cline { 2 - 5 } & $\zeta$ & 0.16 & 0.15 & 6.3 \\
\hline \multirow{2}{*}{$100 \mu \mathrm{m}$} & $f_{n}[\mathrm{~Hz}]$ & 68 & 67 & 1.5 \\
\cline { 2 - 5 } & $\zeta$ & 0.15 & 0.15 & 0 \\
\hline
\end{tabular}

\subsubsection{Effect of rotational speed}

Table 8 lists the identified natural frequencies, damping ratios, and the differences at different rotational speeds. The eccentricities are $100 \mu \mathrm{m}$ and the amplitudes of the d-axis currents are $2.5 \mathrm{~A}$. The natural frequencies and damping ratios were changed slightly depending on the rotational speed due to the variation in stiffness and damping of the oil-film bearings. However, the differences between the identified parameters measured using the suspension windings and the motor windings are less than $7.7 \%$. Therefore, the FRF can be measured using the proposed method.

Table 8 Identified parameters and differences at various rotational speeds.

\begin{tabular}{|c|c|c|c|c|}
\hline \hline & $\begin{array}{c}\text { Suspension } \\
\text { windings (standard) }\end{array}$ & $\begin{array}{c}\text { Motor } \\
\text { windings }\end{array}$ & $\begin{array}{c}\text { Differences } \\
(\%)\end{array}$ \\
\hline \multirow{2}{*}{$20 \mathrm{rps}$} & $f_{n}[\mathrm{~Hz}]$ & 66 & 67 & 1.5 \\
& $\zeta$ & 0.13 & 0.14 & 7.7 \\
\hline \multirow{2}{*}{$30 \mathrm{rps}$} & $f_{n}[\mathrm{~Hz}]$ & 67 & 66 & 1.5 \\
& $\zeta$ & 0.15 & 0.16 & 6.8 \\
\hline \multirow{2}{*}{$40 \mathrm{rps}$} & $f_{n}[\mathrm{~Hz}]$ & 69 & 66 & 4.4 \\
& $\zeta$ & 0.20 & 0.19 & 5.0 \\
\hline
\end{tabular}

\subsubsection{Discussion}

In the experimental results, many of the natural frequencies measured by the suspension winding excitation are higher than those measured by the motor winding excitation. The natural frequency of the rotor system is affected by the bias d-axis currents, as shown in Eq. (11). However, the same bias d-axis currents were set for the rotational control of the motor both in the suspension and motor winding excitations. Another possibility of having a difference in the measured natural frequencies is that the excitation force is not the same in both excitation methods. It may cause the difference in frequency responses due to nonlinear dynamic of the rotor system. For more accurate analysis, further research is required about the effect of the rotor non-linearity.

\section{Conclusion}

This paper proposes a practical method of electromagnetic excitation utilizing the motor windings of a built-in motor to evaluate the dynamic characteristics of turbomachinery. The principle of generating an excitation force utilizing an $\mathrm{AC} \mathrm{d}$-axis current in a rotor with static eccentricity of the rotor is presented. The theoretical equations show that the radial excitation force is not affected by the rotational angle but is proportional to the eccentricity and the d-axis current. A test rig with a BELM was used to verify the feasibility of the proposed method. The FRFs measured utilizing the suspension windings and the motor windings of BELM were compared. The natural frequencies and damping ratios were identified from the two types of FRF. The effectiveness of the proposed method with different rotor dynamics and rotational conditions, such as the eccentricity and rotational speed, was studied. FRF measurements with three different sets of parameters for the rotor dynamics were made and the percentage differences between measurements made with the two different FRFs were less than 5.2\%. The proposed method was verified for different rotational conditions. Even when the 
eccentricity was $25 \mu \mathrm{m}$ and the rotor dynamics were changed by varying the rotational speed, the differences between the natural frequencies and the differences between the damping ratios obtained from the two different FRFs were less than $7.7 \%$.

Future work will focus on extending the proposed electromagnetic excitation, including evaluations using canned motor pumps or artificial blood pumps. Furthermore, sensorless measurement for the displacement will be considered.

\section{Acknowledgement}

This research is partly supported by NSK Foundation for Advancement of Mechatronic.

\section{Reference}

Aenis, M., Knopf, E. and Nordmann, R., Active Magnetic Bearings for the Identification and Fault Diagnosis in Turbomachinery, Mechatronics (Oxf), Vol.12, No.8 (2002), pp.1011-1021.

Chiba, A., Fukao, T., Ichikawa, O., Oshima, M., Takemoto, M. and Dorrell, D. G., Magnetic Bearings and Bearingless Drives (2005), pp.356-360, Elsevier.

Lee, C. I. and Jang, G. H., Experimental Measurement and Simulated Verification of the Unbalanced Magnetic Force in Brushless DC Motors, IEEE Transactions on Magnetics, Vol.44, No.11 (2008), pp.4377-4380.

Liu, J., Gong, C., Han, Z. and Yu, H., IPMSM Model Predictive Control in Flux-Weakening Operation Using an Improved Algorithm, IEEE Transactions on Industrial Electronics, Vol.65, No.12 (2018), pp.9378-9387.

Mwasilu, F., Nguyen, H. T., Choi, H. H. and Jung, J. W., Finite Set Model Predictive Control of Interior PM Synchronous Motor Drives with an External Disturbance Rejection Technique, IEEE/ASME Transactions on Mechatronics, Vol.22, No.2 (2016), pp.762-773.

Nguyen, T. D., Foo, G., Tseng, K. and Vilathgamuwa, D. M., Modeling and Sensorless Direct Torque and Flux Control of a Dual-Airgap Axial Flux Permanent-Magnet Machine with Field-Weakening Operation, IEEE/ASME Transactions on Mechatronics, Vol.19, No.2 (2013), pp.412-422.

Ranjit, J., Current Axial-Flow Devices-The HeartMate II and Jarvik 2000 Left Ventricular Assist Devices, Seminars in Thoracic and Cardiovascular Surgery, Vol.20, No.3 (2008), pp.264-272.

Rezaee-Alam, F., Rezaeealam, B. and Faiz, J., Unbalanced Magnetic Force Analysis in Eccentric Surface PermanentMagnet Motors Using an Improved Conformal Mapping Method, IEEE Transactions on Energy Conversion, Vol.32, No.1 (2016), pp.146-154.

Takahashi, N., Magara, Y., Narita, M. and Miura, H., Rotordynamic Evaluation of Centrifugal Compressor Using Electromagnetic Exciter, Journal of Engineering for Gas Turbines and Power, Vol.134, No.3 (2012), DOI:10.1115/1.4004439.

TEIKOKU Electric Mfg Co Ltd (Japan), Canned Motor Pumps (online), available from <http://www.texasprocess.com/templates/tpe/Assets/teikokubrochure.pdf>, (accessed on 19 June).

Tsunoda, W., Hijikata, W., Shinshi, T., Fujiwara, H. and Matsushita, O., Diagnostic Experiments for Stability of RotorOil Film Bearing Systems Using Radial Magnetic Bearing Excitation, Vibrations in Rotating Machinery, Proceeding of VIRM11, Institute of Mechanical Engineers (2016), pp.13-15.

Tsunoda, W., Wagner, C., Berninger, T., Thuemmel, T. and Rixen, D., Stability Diagnosis for Rotor-Seal System by Utilizing Active Magnetic Bearing, International Symposium on Dynamic Problems of Mechanics (DINAME 2017) (2017a), Paper No. DINAME2017-0048.

Tsunoda, W., Chiba, A. and Shinshi, T., Suppression of Self-Excited Vibration Caused by Oil Film Bearing Using Bearingless Motor, IEEE International Electric Machines \& Drives Conference (IEMDC2017) (2017b), pp.1-6.

Tsunoda, W., Chiba, A. and Shinshi, T., Radial Excitation Force Generated by Permanent Magnet Motor Using d-Axis Current Injection, IEEE International Conference on Industrial Technology (2018), pp.504-509.

Tsunoda, W., Chiba, A. and Shinshi, T., Vibration Control for Rotor Supported by Oil-film Bearings Using Bearingless Motor, IEEE/ASME Transactions on Mechatronics, Vol.24, No.3 (2019a), pp.1368-1375.

Tsunoda, W., Chiba, A. and Shinshi, T., Frequency Response Function Measurement Utilizing Radial Excitation Force Generated by Permanent Magnet Synchronous Motor, Mechatronics, Vol.61, (2019b), pp.49-57. 
Yang, Tsunoda, Han, Zhong and Shinshi,

Journal of Advanced Mechanical Design, Systems, and Manufacturing, Vol.14, No.4 (2020)

Zhang, X. and Foo, G., A Constant Switching Frequency-Based Direct Torque Control Method for Interior PermanentMagnet Synchronous Motor Drives, IEEE/ASME Transactions on Mechatronics, Vol.21, No.3 (2015), pp.14451456. 